\title{
Intraspecific dental variations in the deep-sea shark Etmopterus spinax and their significance in the fossil record
}

\author{
Nicolas Straube ${ }^{1} \mathbb{D} \cdot$ Jürgen Pollerspöck ${ }^{2}$ (D)
}

Received: 10 August 2020 / Revised: 28 September 2020 / Accepted: 3 October 2020 / Published online: 26 October 2020

(c) The Author(s) 2020

\begin{abstract}
An important character on several taxonomic levels for shark identification is the tooth morphology. Sharks show a variety of highly specialized dentitions reflecting adaptations to their feeding habits. Intraspecific variation of tooth morphology such as sexual or ontogenetic dimorphism is poorly known in many species, even though tooth morphology plays a decisive role in the characterization of the fossil record of sharks, which comprises mostly fossil teeth. Here we analyzed the dentition of 40 jaws of the Velvet Belly Lantern Shark Etmopterus spinax and identified ontogenetic and sexual dimorphic characters such as total number of teeth, number of upper teeth, cusplet numbers in upper jaw teeth and width of lower jaw teeth. Dimorphic characters may reduce intraspecific competition for food, as E. spinax segregates by sex and size and may allow for identifying the male sex. The lower jaw tooth height, a sexually non-dimorphic character, was used to re-calculate the total length of specimens, which represents the first such approach for a squaliform shark. Results derived from the extant E. spinax are subsequently applied to fossil Etmopterus sp. teeth (Miocene) to gain individual information such as sex or size, but also characterize the extinct population from the excavation site by a size distribution profile in comparison to data from extant populations. This approach indicates the presence of multiple ontogenetic stages in the extinct population.
\end{abstract}

Keywords Dentition $\cdot$ Fossil $\cdot$ Shark $\cdot$ Squaliform $\cdot$ Sexual dimorphism $\cdot$ Ontogenetic dimorphism

\section{Introduction}

The fossil record of modern sharks (Neoselachii) dates back to the Triassic (Maisey 2012) and the majority of fossil evidence comprises teeth only. While articulated fossils are scarce, numerous dental fossils form a rather detailed fossil record partially documenting the evolutionary history of taxa quite detailed (Maisey 2012). The reason for this lies in the sharks' ability to replace teeth continuously throughout their lifetime (Luer et al. 1990; Overstrom 1991; Reif et al. 1978), depositing numerous organic matter in the environment,

Electronic supplementary material The online version of this article (https://doi.org/10.1007/s00435-020-00503-3) contains supplementary material, which is available to authorized users.

Nicolas Straube

nicolas.straube@uib.no

1 Department of Natural History, University Museum of Bergen, Realfagbygget, Allégaten 41, 5020 Bergen, Norway

2 Benediktinerring 34, 94569 Stephansposching, Germany which is ideal for fossilization due to its composition. Contrasting, the cartilage skeleton is less suited for fossilization and is only fragmentary or not at all preserved.

The tooth morphologies of living species are the basis for identifying both extant as well as extinct taxa in the fossil record. Today, 547 described living species contrast 2608 extinct species, which description is mostly based on teeth and therefore dental morphological characters (Pollerspöck and Straube 2020). Intraspecific morphological variation is documented in some living species (e.g. Ellis and Shackley 1995; Moyer and Bemis 2016; Purdy and Francis 2007; Sadowsky 1970; Straube et al. 2008; Taniuchi 1970), however, it is unknown for most, especially in deep-sea sharks (Cullen and Marshall 2019; Martins et al. 2015; Pinchuk and Permitin 1970). The known cases comprise ontogenetic differences (Mello and Brito 2013), which may be due to differences in diet (French et al. 2017; Powter et al. 2010; Raschi et al. 1982; Reif 1976; Schwartz and Hurst 1996; Tomita et al. 2017) as well as seasonal changes due to sexual or population-level differences (Lucifora et al. 2003). Therefore, it is possible that the presence of intraspecific variation 
in tooth morphologies in extant species is more common than documented.

In the fossil record, intraspecific and intraindividual variation in tooth morphology pose a challenge, as multiple fossil teeth found in excavation sites per se do not allow to draw conclusions how many individuals lost these teeth. Further, in case of unknown intraspecific dental morphological variation, which sex(es) and ontogenetic stages were involved or potential morphological congeners.

In this study, we analyze the intraspecific variation of a single deep-sea shark species, Etmopterus spinax. Etmopterus is the most species rich shark genus, with 44 species described today (Pollerspöck and Straube 2020). E. spinax is eponymous for the E. spinax clade, one of the four subclades of the genus identified in Straube et al. (2010). Except for adults of a single species, E. sheikoi, all other Etmopterus species are characterized by a dignathic heterodonty showing multicuspid upper jaw teeth, which are likely used to hold onto prey and single-cusped, overlappingly arranged lower teeth, which form a cutting edge [cutting-clutching type dentition (Cappetta 2012)]. These distinct morphological features allow for identifying a number of fossil forms dating back to the Upper Cretaceous. Using the fossil record to date the divergence times of Etmopterus estimated the rise of the genus to the end of the Cretaceous and the divergence of the four subclades to the Eocene, where the different subgroups split in a time frame of approximately 13 million years (Eocene, Oligocene; 37-24 million years) (Straube et al. 2010, 2015). Even though dental characters play a role in some Etmopterus species identifications (e.g. Adnet et al. 2006; Chan 1966; Dolganov 1986), little is known on intraspecific variation, except for few studies (e.g. Herman et al. 1989; Straube et al. 2008).

Here we focus on identifying general dental morphological variation of $E$. spinax within single jaws and further identify differences between sexes and different ontogenetic stages. The results are then applied to fossil Miocene Etmopterus sp teeth and conclusions are drawn on the former carrier.

\section{Materials and methods}

\section{Materials}

We analyzed $N=40$ jaws from the Velvet Belly Lantern Shark E. spinax. Please see Supplementary Table 1 for an overview of specimens analyzed and collection information. The specimens were stored frozen and are deposited in the specimen collection of Henrik Glenner's research group, Marine Biodiversity, Department of Biological Sciences (BIO), University of Bergen (see also Rees et al. 2019). The analyzed sample of $E$. spinax specimens comprise 23 male and 17 female individuals of different ontogenetic stages (Supplementary Table 1).

\section{Methods}

Frozen specimens were thawed, the total length measured, and the sex determined. Size classes were categorized representing individuals up to $20 \mathrm{~cm}$ TL, individuals between 20 and $30 \mathrm{~cm}$ TL and individuals $>30 \mathrm{~cm}$ TL. Jaws were dissected from frozen specimens and dried for $2-3 \mathrm{~h}$ at $45^{\circ} \mathrm{C}$. For further preparation at a later point in time, the jaws were placed for $1-2 \mathrm{~min}$ in $95{ }^{\circ} \mathrm{C}$ water and thereafter tissue remains were manually removed. For all jaws, where the condition allowed for, the dental formulas were determined, i.e. the number of teeth was determined for the functional row of upper and lower jaws including sub-sectioning in right and left parts of jaws counting from the symphysis.

In total, 148 teeth were dissected from the $E$. spinax jaws for individual analysis. For this preparation step, the jaws were rehydrated in water for 1-2 min and teeth from the right part of jaws manually dissected using needles and tweezers. All teeth were separately cleaned in a $0.6 \mathrm{~mol} / \mathrm{l}$ $\mathrm{KOH}$ solution for $60 \mathrm{~min}$. After $\mathrm{KOH}$ digestion, teeth were rinsed with water at room temperature and pasted onto stubsized stickers usually used for scanning electron microscopy.

Photographic images of teeth were taken under $40 \times$ magnification with a Leica ID 80 HD digital camera mounted on a Wild M3 Zoom stereomicroscope. Images were edited using the Leica internal camera software LAS EZ version 3.2.1. Lighting was provided by a light tent and additional LED lighting. Where necessary, stacking was used to create continuous definition of images. Combine $Z$ vers 2010 was used to combine images for stacking. Gimp vers. 2.10.4 was used for final editing steps.

For the upper jaw teeth we counted the number of lateral cusplets (Fig. 1a) in $N=40$ jaw specimens in the functional rows of teeth. The lower jaw tooth height was measured (Fig. 1b) for a single tooth of $N=40$ jaw specimens. The tooth was chosen from one of the positions 6-10 of the left lower jaws counting from the symphysis in case the targeted teeth were worn, broken or missing. For specimens 1250 (male) and 1253 (female) all functional row teeth were dissected out and measured. Additionally, the width of the lower jaw teeth was measured in these two specimens, as this can only be done, when teeth are dissected, as in the single lower jaw functional row teeth are overlappingly arranged and connected by a ligament.

For the classification of fossil Etmopterus sp. teeth we used 16 lower jaw tooth specimens, ten from Pollerspöck and Straube (2017) and six newly collected for this study as well as a single upper jaw tooth. Fossil teeth newly 


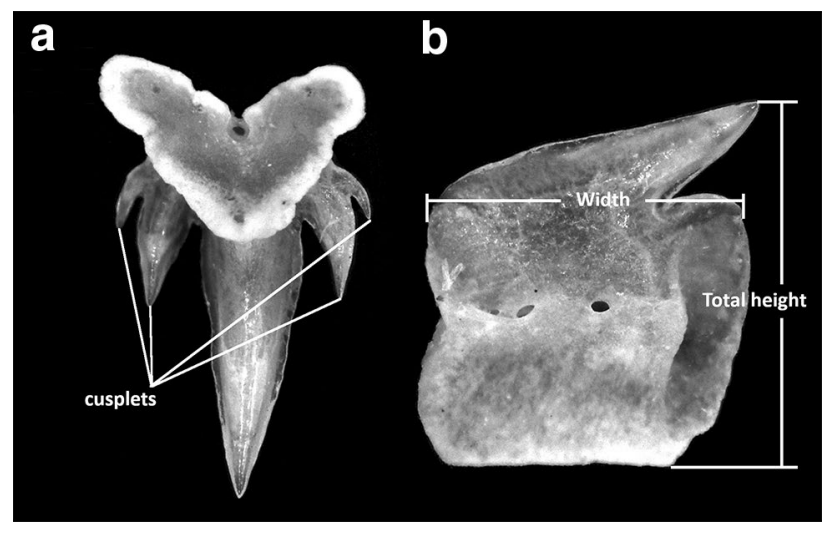

Fig. 1 Morphometric and meristic data collected of Etmopterus spinax teeth. a Upper jaw tooth. b Lower jaw tooth

collected for this study were excavated in 2019 at Mitterdorf (Neuhofener Beds) following the protocol described in Pollerspöck and Straube (2017). Data on the fossil teeth were analoguously collected as for the $E$. spinax teeth (Fig. 1). For estimating the total lengths of specimens based on single lower jaw teeth, we used the equation describing the trendline when plotting lower tooth height against total length of the E. spinax specimens as: data. All specimen details and data are provided in Supplementary Table 1.

\section{Results}

\section{Jaws and teeth of Etmopterus spinax}

On average, an E. spinax jaw contained 55 teeth. Twentyfour in upper, 31 in lower jaws. Upper and lower jaw teeth were continuously decreasing in size from the symphysis towards the rears of the mouth (Fig. 2). In upper jaws, there were usually two functional rows of teeth as well as 2-3 replacement rows. See Table 1 for a summary of dental information for the three size groups. Upper jaw teeth were replaced one by one. The number of cusplets in upper jaw teeth varied from 1 to 6 cusplets. Contrasting, there was only a single functional row of teeth in the lower jaws. Lower jaw teeth were connected through a ligament and overlapping areas. The complete functional row was replaced. There were usually 3-4 replacement rows in lower jaws. Lower jaw teeth bore a single cusp only, which was bent distally. Figure 2 illustrates the dental morphological variation between sexes and ontogenetic groups.

$y($ tooth height in $\mu)=m($ gradient $) x($ total length in $\mathrm{cm})+b(y$-intercept $)$.

This trendline is characterized by a gradient $m=39.225$ and a $y$-intercept $=113.71$. Thereafter, we solved the equation for $x$ (total length in $\mathrm{cm}$ ) calculating the total length as:

$x($ total length in $\mathrm{cm})=(y($ tooth height in $\mu)-113.71) / 39.225$.

As a proof of concept, we used lower jaw tooth heights measured in one jaw half of a single male and a single female E. spinax jaw (TL $=35 \mathrm{~cm}$ for both specimens, specimens 1250 und 1253; Supplementary Table 1) to recalculate the total length of specimens 1250 (male) and 1253 (female) following the above equation.

Further, we conducted a literature research to collect information on the size distribution of different North East Atlantic and Mediterranean E. spinax populations. For that we analyzed data from Neiva et al. (2006), Borges et al. (2002) and Fanelli et al. (2009) and computed the total length distributions (Supplementary Table 1).

We used PAST vers. 3 (Hammer et al. 2001) for performing two sample $t$ tests for comparing sexes and three different size groups representing ontogenetic stages (Table 1). The number of cusplets of upper teeth was compared between sexes and the three ontogenetic groups. Excel and PAST were used for graphic analyses of the

\section{Sexual and ontogenetic differences in tooth morphology and meristics}

A sexual difference was detected in the total number of teeth between sexes, where males showed an increase in total tooth numbers with increasing size, i.e. male and female specimens of the same body size differed in the number of jaw teeth (Fig. 3a). The difference got more distinct with increasing size (Fig. 3b), which manifested in a significant difference of upper tooth numbers between males and females in the group of specimens with a total length $\geq 30 \mathrm{~cm}$ (two sample $t$ test; $p$ (same mean) $=0.01$; Fig. 3b). Given that male specimens showed more teeth at the same size, females seemed to compensate for that by larger teeth. The width of lower teeth was significantly different between specimens 1250 (male) and 1253 (female) (two sample $t$ test; $p$ (same mean) $=0.0001$; Fig. $3 \mathrm{c}$ ). We further detected a significant difference in the number of cusplets in upper teeth in size groups 2 and 3 (two sample $t$ test; $p$ (same mean group 2$)=0.05 ; p($ same mean group $2)=0.03$ ). Males developed a larger number of cusplets (Fig. 3d). 
Fig. 2 Morphological variation between sexes and ontogenetic groups. $T L$ total length in $\mathrm{cm}$. If possible, specimens of similar or same sizes were compared at similar or same tooth positions depending on conditions. $U J$ upper jaw, $L J$ lower jaw, $l$ left from symphysis. Further specimen details are given in Supplementary Table 1

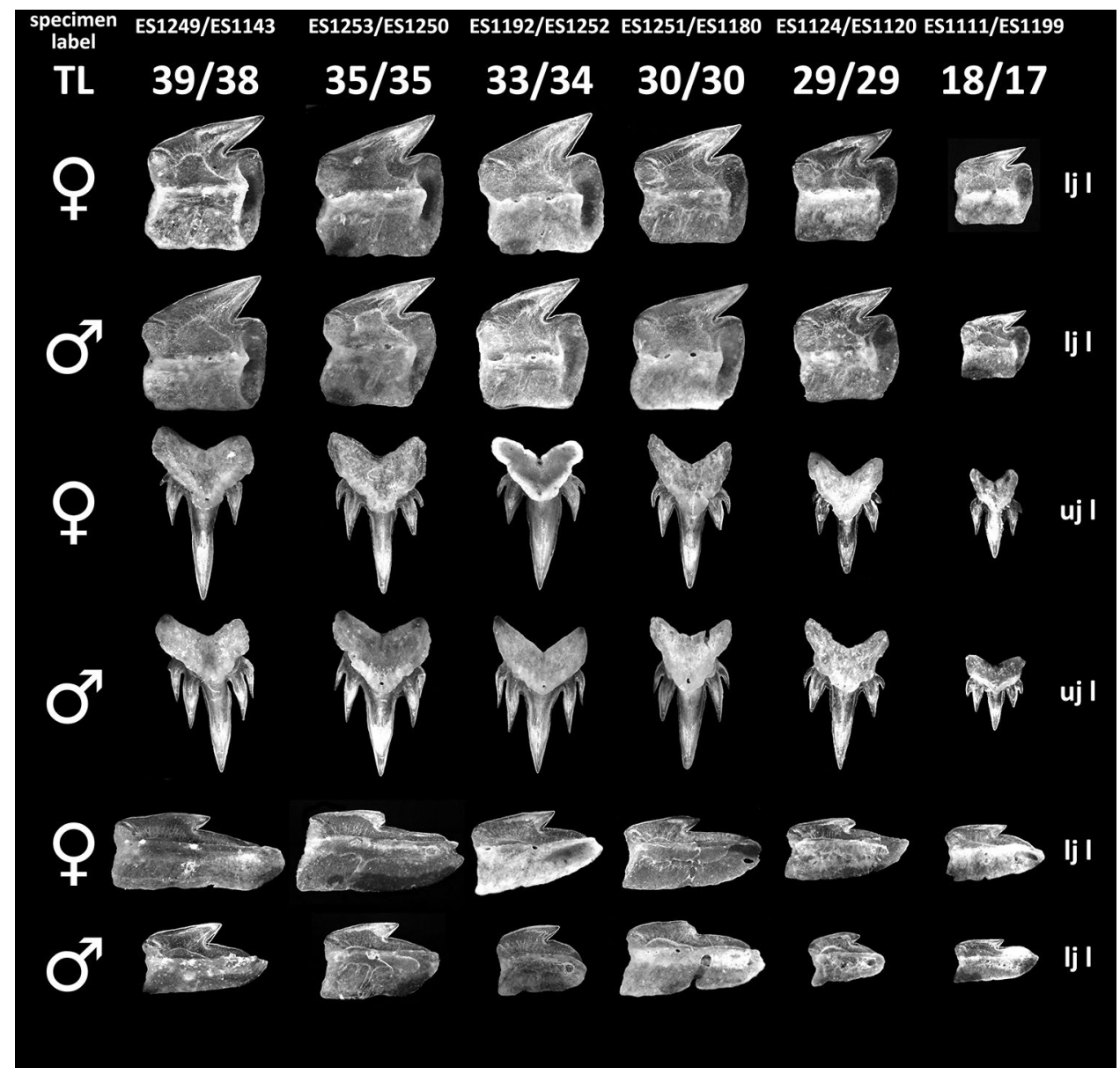

Table 1 Ontogenetic groups and details of tooth numbers of analyzed Etmopterus spinax jaws

\begin{tabular}{lllll}
\hline Size in cm & Upper jaw & Lower jaw & Total & Dental formula \\
\hline$\leq 20$ female & 22.20 & 26.60 & 48.80 & $20-24 / 26-27$ \\
$\leq 20$ male & 22.67 & 27.00 & 49.67 & $21-26 / 24-31$ \\
$>20 \leq 30$ female & 23.67 & 30.17 & 53.83 & $21-26 / 27-31$ \\
$>20 \leq 30$ male & 25.17 & 31.67 & 56.83 & $22-26 / 24-29$ \\
$>30$ female & 23.00 & 32.67 & 55.67 & $20-24 / 30-35$ \\
$>30$ male & 27.09 & 33.91 & 61.00 & $22-30 / 30-38$ \\
Total female & 23.00 & 30.00 & 53.00 & $20-26 / 26-35$ \\
Total male & 25.43 & 31.52 & 56.96 & $21-30 / 24-35$ \\
\hline
\end{tabular}

\section{Fossil teeth}

Etmopterus spinax upper teeth gradually decreased towards the rears of the mouth. Therefore, any measurements were biased and not suitable to calculate the former total length of the bearer of a fossil tooth. In contrast, the height of the lower teeth remained relatively stable in tooth positions one to ten making them ideal candidates for the estimation of the total lengths of the fossil specimens. Lower jaw teeth from positions 11 and beyond were also easy to identify due to the distinct change of the root morphology, which gained a trapezoidal shape in the rears of jaws, from tooth position 11 ascending. Results from our approach to re-calculate total lengths of E. spinax specimens 1250 (male) and 1253 (female) were widely successful for anterior tooth positions. For male specimen 1250 (male), we were able to recover the total length for tooth positions 1-12 with a variety of $1 \mathrm{~cm}$. Posterior teeth (positions 13-17) showed a larger fluctuation of total length estimates with a variation of 3-11 cm. Commissure teeth (position 16 of ES1253 and position 18 of ES1250) were not considered for measurements due to their distinct morphology (Fig. 2). A similar situation was present in the female specimens. Teeth from positions 1 to 12 showed a variation in re-computed total lengths of $3 \mathrm{~cm}$, while posterior teeth (positions 13-15) showed a variation of $2-10 \mathrm{~cm}$. Posterior lower jaw teeth were therefore not suitable for total length estimations.

Estimating the former total lengths based on the height of lower jaw teeth of 16 fossil Etmopterus sp. specimens resulted in two specimens assignable to the size group $<20 \mathrm{~cm}$ TL, seven specimens to size group 20-29 cm TL and seven specimens to size group $>30 \mathrm{~cm}$ 
a

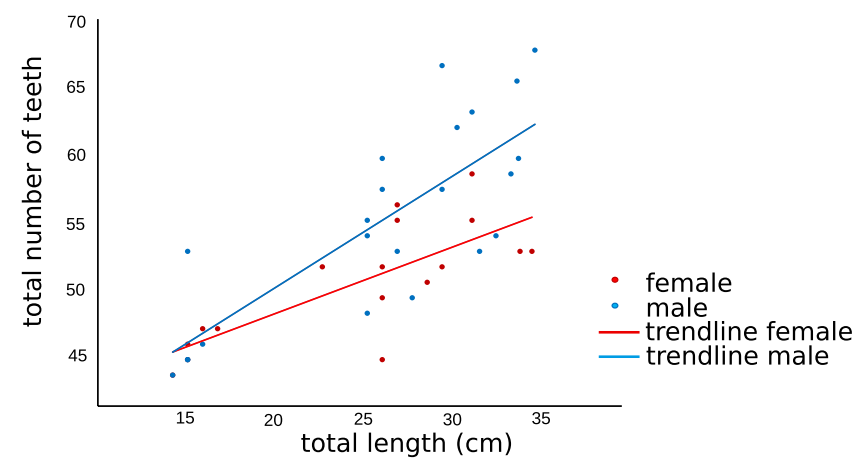

C

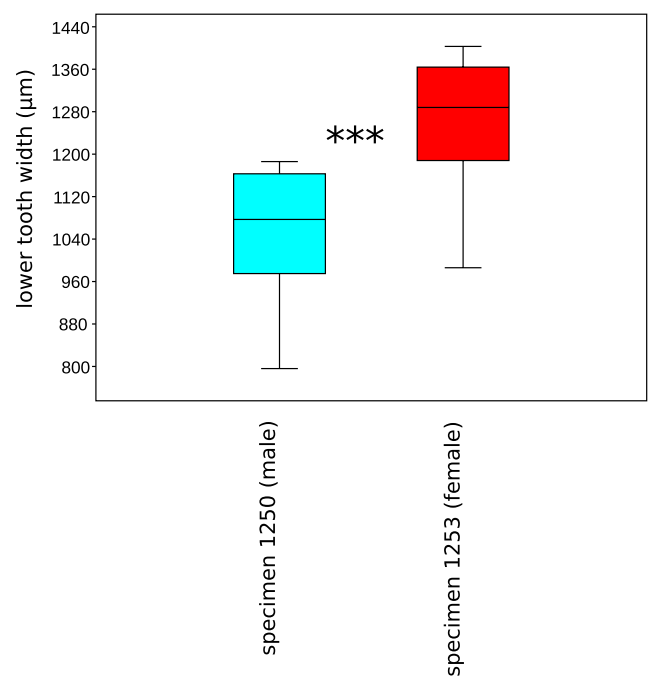

Fig. 3 Sexual and ontogenetic differences in tooth morphology and meristics. $* p<0.05$; $* * p<0.01$; $* * * p<0.000$. a Ontogenetic differences in total number of jaw teeth between sexes of Etmopterus spinax. Details on specimens are given in Supplementary Table 1. b Boxplots showing the development of upper jaw tooth numbers of

TL. The minimum and maximum estimated sizes were 15 and $36 \mathrm{~cm}$ TL (Supplementary Table 1). The lower jaw teeth did not allow for any conclusions on the sexes of the fossils.

Literature research in combination with our sampling allowed us to generate a representative profile of the size distribution of the North East Atlantic and Mediterranean $E$. spinax populations and compare to the findings in the fossil record. Even though the fossil sampling was much smaller, the size distribution profile is similar to the profile derived from data of the extant population (Fig. 4). This approach could therefore be used in continuative studies to draw conclusions on total length distributions in extinct populations. b

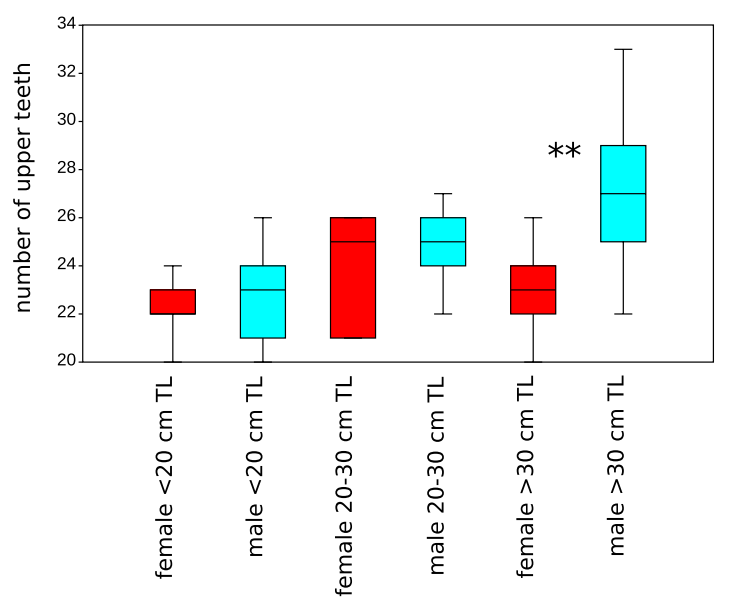

d

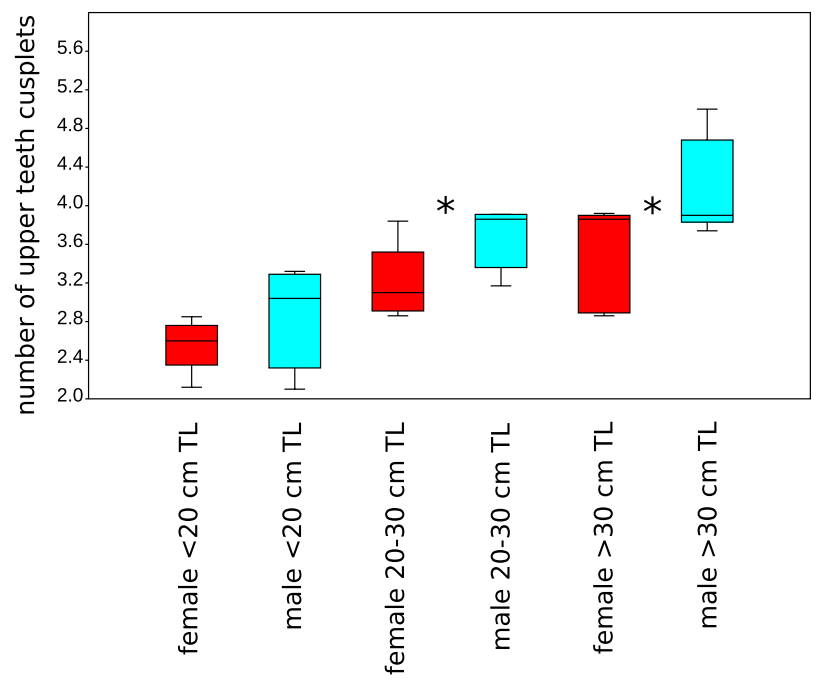

Etmopterus spinax between sexes of different size groups representing ontogenetic stages. c Difference in width of lower teeth of specimens 1250 (male) and 1253 (female). d Boxplots showing the development of upper jaw tooth cusplet numbers of Etmopterus spinax between sexes of different size groups representing ontogenetic stages

\section{Discussion}

The number of extinct shark species surpasses the number of extant species more than five times. As Purdy and Francis (2007) state, numerous genera and species of extinct sharks have been described in the fossil record lacking detailed knowledge on intraspecific and intraindividual variation of tooth morphologies of extant species. In this study, we contribute to a better understanding of the intraspecific and intraindividual dental variation in Etmopterus, hitherto the most diverse extant shark genus (Pollerspöck and Straube 2020). We detected both sexual and ontogenetic dental differences in the total number of 


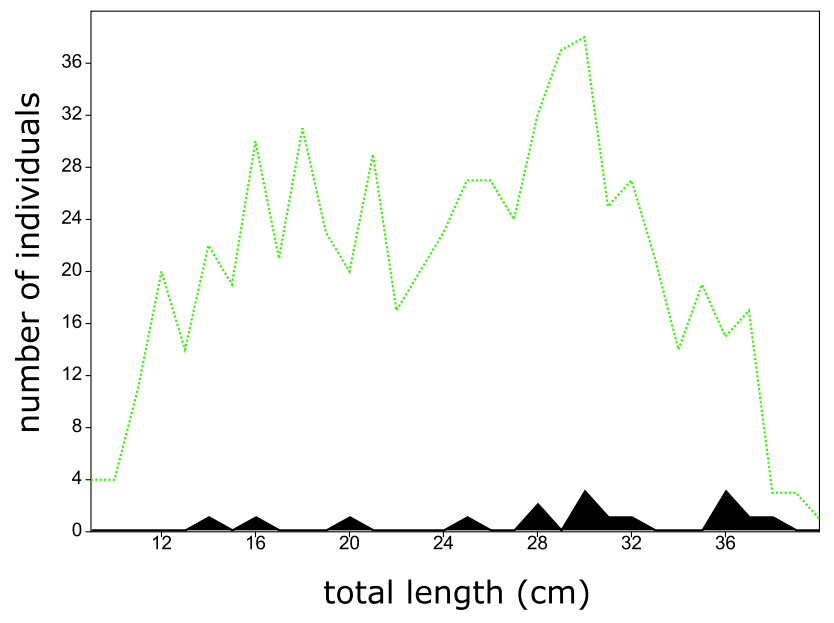

Fig. 4 Size distribution of Etmopterus spinax in the North East Atlantic and Mediterrenean (green dotted line) based on literature records (Neiva et al. 2006; Borges et al. 2002; Fanelli et al. 2009) and reconstructed size distribution of Etmopterus sp. fossils analyzed (black)

teeth, the number of upper teeth, the number of upper teeth cusplets as well as the width of lower teeth (Fig. 3).

\section{Intraspecific dental variation}

As variations documented for E. spinax in this study align with variations reported in Straube et al. (2008) for Etmopterus granulosus (Günther, 1880), the variability may be typical in other species of the E. spinax clade, if not in all species of the genus Etmopterus. The variable characters can be summarized to affect total tooth numbers, lower jaw teeth width, number of cusplets in upper teeth, position in jaws and root morphology. We found both ontogenetic and sexual dental differences, which seem to be linked. Ontogenetic differences in the total lengths of E. spinax (and other Etmopterus species) were the only sexually dimorphic morphological characters known. With increasing size (and age) the differences between males and females get more pronounced and are most prominent in specimens $>30 \mathrm{~cm}$ TL (Fig. 3b, d). The size at maturity in E. spinax is about $25.3-35 \mathrm{~cm}$ TL in males and 30.8-38 cm TL in females (Porcu et al. 2014), we therefore conclude that the dental differences are connected to size at maturity. E. spinax is known to segregate by sex and size (Mauchline and Gordon 1983; Massutí and Moranta 2003), the sexually dimorphic dentition may reflect further ecological niche establishment. Stomach content analysis show that $E$. spinax is an opportunistic feeder on a rather low trophic level (Bengil et al. 2019). Its prey items comprise mainly teleosts, cephalopods and crustaceans (Fanelli et al. 2009; Neiva et al. 2006). E. spinax undergoes two diet shifts at $15-25 \mathrm{~cm}$ TL and $25-45 \mathrm{~cm}$ TL (Fanelli et al. 2009; Neiva et al. 2006), the latter falls in the range of the sexual dental dimorphisms documented herein. However, Neiva et al. (2006) state that the diet shifts are not connected to sex or maturity but size only due to an increase in mouth dimension accompanied by larger flexibility in prey selection. Some sexual variation in diet was explained by depth segregation of sexes after reaching maturity and accompanying food resource differences. Our results may add an ecological segregatory factor, as dentitions may have adapted to different food sources caused by depth segregation for sexes further reducing competition.

Another explanation may be found in a sexual dimorphism related to E. spinax' mating behavior. Even though mating has not been observed in the wild for this species so far, a distinct pairing with embrace as in other sharks is assumed (Breder and Rosen 1966). In that, the male shark grabs the female's pectoral fin (base) with its mouth to ease copulation. More and thinner cusplets in upper jaw teeth may be beneficial to hold onto the female. A mating season modification of teeth from flat (for crushing food) to needle-like teeth in males is known from several ray species, for example Dasyatis americana, Urolophus halleri and Urotrygon microphthalmum. This morphological modification of teeth is linked to mating behavior in these species (Chapman et al. 2003; Nordell 1994; Rangel et al. 2016). If similar reasons increase the number of upper tooth cusplets in males of $E$. spinax remain speculative.

\section{Evaluation of fossil etmopterid teeth}

Our results showed numerous morphological variations in E. spinax, which can be taken into account in studies on fossil etmopterid teeth (Fig. 2). Based on our survey of intraspecific variation, we could extrapolate the former total length of the fossil specimen based on single fossil lower jaw teeth. Even though lower teeth seem to differ between sexes in width (Fig. 3c), the height is stable across sexes and size groups. Therefore, the lower tooth height as measured in Fig. $1 b$ is an adequate character for total length reconstructions (Fig. 4). Total length estimates based on tooth sizes have been conducted on only few shark species so far, mostly lamniform sharks (Applegate 1965; Chavez et al. 2012; Pimiento and Balk 2015; Shimada 2002a, b, 2005, 2006, 2020; Shimada and Seigel 2005). This study is the first such approach for a squaliform shark and can serve as a blueprint for future studies on fossil shark teeth as extant species are the best reference for drawing conclusions on fossil dental morphological variation. Further, our approach is useful in continuative studies on extinct populations or characterization of excavation sites. Given that the size distribution suggests the presence of all ontogenetic stages (Fig. 4), a nursery ground can, therefore, be disregarded. Such interpretations have to be treated with care, however, as the a priori assumption is made that all fossil Etmopterus sp. teeth analyzed herein originate from the same species. 


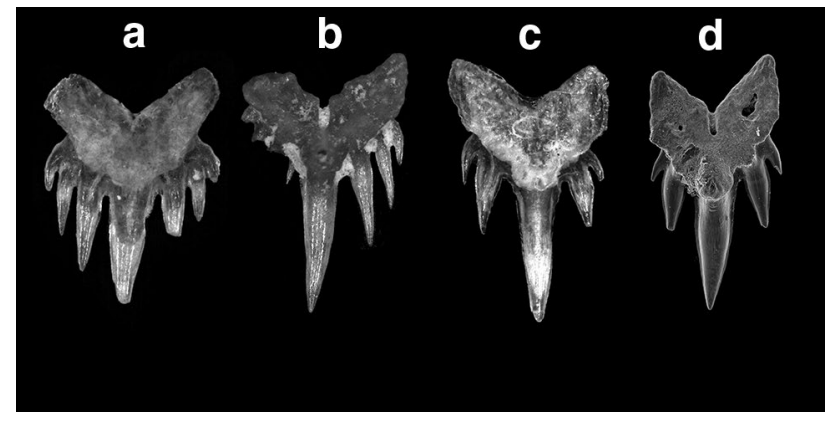

Fig. 5 Comparison of fossil Etmopterus sp. upper teeth with Etmopterus spinax upper teeth. a Adult male upper tooth from specimen ES2020_03 (1st functional row; tooth position 5 counting from symphysis). b Potentially adult male fossil upper tooth with increased number of needle-like cusplets (Miocene, Mitterdorf, Neuhofener Beds, Germany). c Adult female upper tooth from specimen ES 1253 (1st functional row; tooth position 6 counting from symphysis). d Potentially (adult?) female fossil upper tooth with triangular, wider cusplets (from Pollerspöck and Straube 2017, SNSB-BSPG 2015 III 2-21)

Even though we found a significant difference in cusplet numbers of upper teeth between male and female specimens (Fig. 3d), it is difficult to assign a single fossil upper Etmopterus tooth to a sex, as the intraindividual variation of cusplet numbers is high (Fig. 2) and a certain number of cusplets does not necessarily indicate the sex due to the large intraindividual variability. However, the shape of cusplets may allow for distinguishing sexes. Male cusplets appear slenderer, bent and hook-like, while female cusplets seem wider and more triangular in shape. Analyzing this character in detail is difficult, as cusplets are often broken and differences diluted by the high variability as also reported in Straube et al. (2008) for E. granulosus. A distinction of sex based on cusplet numbers in upper teeth maybe possible in other Etmopterus species, however. Straube et al. (2007) report on significant differences in cusplet numbers of two species of the Etmopterus lucifer clade. Even though not analyzed in detail, apart from cusplet numbers, the shape of cusplets also seems to differ between sexes. Further, a single pair of first cusplets, which are smaller than subsequent cusplets seems malespecific. Further data of $E$. spinax teeth may allow to identify more sexually dimorphic characters in the future. We speculate that the upper jaw Etmopterus sp. teeth shown in Pollerspöck and Straube (2017) are from a female specimen, while the newly analyzed fossil upper Etmopterus sp. tooth may originate from a male specimen (Fig. 5).

Acknowledgements We express our sincere thanks to Henrik Glennar (UiB) and David Rees (UiB) for providing access to their specimen collection. We would further like to thank Anne Helene Solberg Tandberg (UiB), the crew of the R. V. Brattstrøm (UiB) and Knut Thomas Sørlie at UiB Espegren Marine Research Facility.
Author contributions NS and JP designed the study and dissected specimens. JP counted, dissected, measured and photographed teeth. NS wrote the manuscript with contributions from JP.

Funding Open Access funding provided by University of Bergen.

Data availability All data analyzed herein is available in Supplementary Table 1 . Specimens are available in the specimen collection of Henrik Glenner's research group, Marine Biodiversity, Department of Biological Sciences (BIO), University of Bergen.

\section{Compliance with ethical standards}

Conflict of interest The authors declare that they have no conflict of interests.

Open Access This article is licensed under a Creative Commons Attribution 4.0 International License, which permits use, sharing, adaptation, distribution and reproduction in any medium or format, as long as you give appropriate credit to the original author(s) and the source, provide a link to the Creative Commons licence, and indicate if changes were made. The images or other third party material in this article are included in the article's Creative Commons licence, unless indicated otherwise in a credit line to the material. If material is not included in the article's Creative Commons licence and your intended use is not permitted by statutory regulation or exceeds the permitted use, you will need to obtain permission directly from the copyright holder. To view a copy of this licence, visit http://creativecommons.org/licenses/by/4.0/.

\section{References}

Adnet S, Cappetta H, Nakaya K (2006) Dentition of etmopterid shark Miroscyllium (Squaliformes) with comments on the fossil record of lanternsharks. Cybium 30:305-312

Applegate SP (1965) Tooth terminology and variation in sharks with special reference to the sand shark, Carcharias taurus Rafinesque. Los Angeles Co Mus Contr Sci 86:1-18

Bengil F, Bengil EG, Mavruk S, Heral O, Karaman OD, Ozaydin O (2019) Feeding ecology of four demersal shark species (Etmopterus spinax, Galeus melastomus, Scyliorhinus canicula and Squalus blainville) from the eastern Aegean sea. Turk J Fish Aquat Sci 19:475-484. https://doi.org/10.4194/1303-2712-v19_6_03

Borges TC, Costa E, Cristo M, Erzini K, Malaquias A, Nortista P, Olim S, Pais C, Sendão J, Campos A, Fonseca P, Santos J, Larsen R, Eide A, Broadhurst M (2002) Managing by-catch and discards: a multidisciplinary approach ("Bydiscard"). Study Project No. 99/058 Final Report to the European Commission Directorate General Fisheries 2002

Breder CM, Rosen DE (1966) Modes of reproduction in fishes. T.F.H. Publications, Neptune City

Cappetta H (2012) Handbook of paleoichthyology, vol. 3e: chondrichthyes-mesozoic and cenozoic elasmobranchii: teeth. Friedrich Pfeil, Munich

Chan WL (1966) New sharks from the South China sea. J Zool 146:218-237. https://doi.org/10.1111/j.1469-7998.1966.tb029 49.x

Chapman DD, Corcoran MJ, Harvey GM, Malan S, Shivji MS (2003) Mating behavior of southern stingrays, Dasyatis americana (Dasyatidae). Environ Biol Fish 68:241-245. https://doi. org/10.1023/A:1027332113894 
Chavez S, Zufan S, Kim SH, Shimada K (2012) Tooth sizes as a proxy for estimating body lengths in the porbeagle shark, Lamna nasus. J Foss Res 45:1-5

Cullen JA, Marshall CD (2019) Do sharks exhibit heterodonty by tooth position and over ontogeny? A comparison using elliptic Fourier analysis. J Morphol 280:687-700. https://doi.org/10.1002/ jmor.20975

Dolganov VN (1986) Description of new species of sharks of the family Squalidae (Squaliformes) from the north-western part of the Pacific Ocean with remarks of validity of Etmopterus frontimaculatus. Zool Zh 65:149-153

Ellis JR, Shackley SE (1995) Ontogenic changes and sexual dimorphism in the head, mouth and teeth of the lesser spotted dogfish. J Fish Biol 47:155-164. https://doi.org/10.1111/j.1095-8649.1995. tb01881.x

Fanelli E, Rey J, Torres P, Gil De Sola L (2009) Feeding habits of blackmouth catshark Galeus melastomus Rafinesque, 1810 and velvet belly lantern shark Etmopterus spinax (Linnaeus, 1758) in the western Mediterranean. J Appl Ichthyol 25(S1):83-93. https ://doi.org/10.1111/j.1439-0426.2008.01112.x

French GCA, Stürup M, Rizzuto S, Van Wyk JH, Edwards D, Dolan RW, Wintner SP, Towner AV, Hughes WOH (2017) The tooth, the whole tooth and nothing but the tooth: tooth shape and ontogenetic shift dynamics in the white shark Carcharodon carcharias. J Fish Biol 91:1032-1047. https://doi.org/10.1111/jfb.13396

Hammer Ø, Harper DAT, Ryan PD (2001) PAST: paleontological statistics software package for education and data analysis. Palaeontol Electron 4(1):1-9

Herman J, Hovestadt-Euler M, Hovestadt DC (1989) Contributions to the study of the comparative morphology of teeth and other relevant ichthyodorulites in living superspecific taxa of Chondrichthyan fishes. Part A: Selachii. no. 3: order: Squaliformes - families: Echinorhinidae, Oxynotidae and Squalidae. Bulletin de l'Institut Royal des Sciences Naturelles de Belgique, Biologie 59:101-158

Lucifora LO, Cione AL, Menni RC, Escalante AH (2003) Tooth row counts, vicariance, and the distribution of the sand tiger shark, Carcharias taurus. Ecography 26:567-572. https://doi.org/10.1 034/j.1600-0587.2003.03532.x

Luer CA, Blum PC, Gilbert PW (1990) Rate of tooth replacement in the nurse shark, Ginglymostoma cirratum. Copeia 1990:182-191

Maisey JG (2012) What is an "elasmobranch"? The impact of palaeontology in understanding elasmobranch phylogeny and evolution.' J Fish Biol 80:918-951. https://doi.org/10.111 1/j.1095-8649.2012.03245.x

Martins APB, Da Silva FE, Feitosa LM, Silva LPN, De Almeida ZS, Nunes JLS (2015) Sexual dimorphism of sharks from the amazonian equatorial coast. Univ Sci 20:297-304. https://doi. org/10.11144/Javeriana.SC20-3.sdos

Massutí E, Moranta J (2003) Demersal assemblages and depth distribution of elasmobranchs from the continental shelf and slope off the Balearic Islands (western Mediterranean). ICES J Mar Sci 60:753-766. https://doi.org/10.1016/S1054-3139(03)00089-4

Mauchline J, Gordon JDM (1983) Diets of the sharks and chimaeroids of the Rockall Trough, northeastern Atlantic Ocean. Mar Biol 75:269-278. https://doi.org/10.1007/BF00406012

Mello WC, Brito PMM (2013) Contributions to the tooth morphology in early embryos of three species of hammerhead sharks (Elasmobranchii: Sphyrnidae) and their evolutionary implications. C R Biol 336:466-471. https://doi.org/10.1016/j.crvi.2013.04.017

Moyer JK, Bemis WE (2016) Tooth microstructure and replacement in the gulper shark, Centrophorus granulosus (Squaliformes: Centrophoridae). Copeia 104:529-538. https://doi.org/10.1643/ CI-15-288

Neiva J, Coelho R, Erzini K (2006) Feeding habits of the velvet belly lanternshark Etmopterus spinax (Chondrichtyes: Etmopteridae) off the Algarve, southern Portugal. J Mar Biol Assoc UK 86:835841. https://doi.org/10.1017/S0025315406013762

Nordell SE (1994) Observations of the mating behavior and dentition of the round stingray, Urolophus halleri. Environ Biol Fish 39:219-229. https://doi.org/10.1007/BF00005124

Overstrom NA (1991) Estimated tooth replacement rate in captive sand tiger sharks (Carcharias taurus Rafinesque, 1810). Copeia 1991:525-526

Pimiento C, Balk A (2015) Body-size trends of the extinct giant shark Carcharocles megalodon: a deep-time perspective on marine apex predators. Paleobiology 41:479-490. https://doi.org/10.1017/ pab.2015.16

Pinchuk VI, Permitin YY (1970) New data on dogfish sharks of the Family Squalidae in the southeastern Atlantic. J Ichthyol 10:273-276

Pollerspöck J, Straube N (2017) A new deep-sea elasmobranch fauna form the Central Paratethys (Neuhofener Beds, Mitterdorf, near Passau, Germany, Early Miocene, Middle Burdigalian). Zitteliana 90:27-53

Pollerspöck J, Straube N (2020) Bibliography Database of living/fossil sharks, rays and chimaeras (Chondrichthyes: Elasmobranchii, Holocephali) https://shark-references.com/. Accessed 27 July 2020

Porcu C, Marongiu MF, Follesa MC, Bellodi A, Mulas A, Pesci P, Cau A (2014) Reproductive aspects of the velvet belly Etmopterus spinax (Chondrichthyes: Etmopteridae), from the central western Mediterranean Sea. Notes on gametogenesis and Oviducal Gland Microstructure. Mediterr Mar Sci 15:313-326. https://doi. org/10.12681/mms.559

Powter DM, Gladstone W, Platell M (2010) The influence of sex and maturity on the diet, mouth morphology and dentition of the Port Jackson shark, Heterodontus portusjacksoni. Mar Freshw Res 61:74-85. https://doi.org/10.1071/MF09021

Purdy RW, Francis MP (2007) Ontogenetic development of teeth in Lamna nasus (Bonnaterre, 1758) (Chondrichthyes: Lamnidae) and its implications for the study of fossil shark teeth. J Vertebr Paleontol 27:798-810. https://doi.org/10.1671/02724634(2007)27[798:ODOTIL]2.0.CO;2

Rangel BS, Santander-Neto J, Rici REG, Lessa R (2016) Dental sexual dimorphism and morphology of Urotrygon microphthalmum. Zoomorphology 135:367-374. https://doi.org/10.1007/s0043 5-016-0312-0

Raschi W, Musick JA, Compagno LJV (1982) Hypoprion bigelowi, a synonym of Carcharhinus signatus (Pisces: Carcharhinidae), with a description of ontogenetic heterodonty in this species and notes on its natural history. Copeia 1982:102-109

Rees DJ, Noever C, Finucci B, Schnabel K, Leslie RE, Drewery J, Theil HO, Dutilloy A, Glenner H (2019) De novo innovation allows shark parasitism and global expansion of the barnacle Anelasma squalicola. Curr Biol 29:R562-R563. https://doi.org/10.1016/j. cub.2019.04.053

Reif WE (1976) Morphogenesis, pattern formation and function of the dentition of Heterodontus (Selachii). Zoomorphologie 83:1-47

Reif WE, McGill D, Motta PJ (1978) Tooth replacement rates of the sharks Triakis semifasciata and Ginglymostoma cirratum. Zool Jahrb Allg Zool 99:151-156

Sadowsky V (1970) On the dentition of the sand shark, Odontaspis taurus, from the vicinity of Cananéia, Brazil. Bol Inst Oceanogr Univ São Paulo 18:37-44

Schwartz FJ, Hurst JM (1996) Tooth surface area comparisons, by sex and age, for Atlantic sharpnose sharks (Rhizoprionodon terraenovae, Carcharhinidae) from North Carolina. J Elisha Mitch Sci Soc 112:87-93

Shimada K (2002a) The relationship between the tooth size and total body length in the shortfin mako, Isurus oxyrinchus (Lamniformes: Lamnidae). J Foss Res 35:6-9 
Shimada K (2002b) The relationship between the tooth size and total body length in the white shark, Carcharodon carcharias (Lamniformes: Lamnidae). J Foss Res 35:28-33

Shimada K (2005) The relationship between the tooth size and total body length in the sandtiger shark, Carcharias taurus (Lamniformes: Odontaspididae). J Foss Res 37:76-81

Shimada K (2006) The relationship between the tooth size and total body length in the common thresher shark, Alopias vulpinus (Lamniformes: Alopiidae). J Foss Res 39:7-11

Shimada K (2020) The size of the megatooth shark, Otodus megalodon (Lamniformes: Otodontidae), revisited. Hist Biol. https://doi. org/10.1080/08912963.2019.1666840

Shimada K, Seigel JA (2005) The relationship between the tooth size and total body length in the goblin shark, Mitsukurina owstoni (Lamniformes : Mitsukurinidae). J Foss Res 38:49-56

Straube N, Kriwet J, Schliewen U, Tanaka S (2007) Males are different: sexual dimorphism of upper teeth in (two) species of latern sharks (Chondrichthyes: Etmopteridae). Abstract Annual Meeting of the European Elasmobranch Association 2007, Brest, France

Straube N, Schliewen U, Kriwet J (2008) Dental structure of the giant lantern shark Etmopterus baxteri (Chondrichthyes: Squaliformes) and its taxonomic implications. Environ Biol Fish. https://doi. org/10.1007/s10641-007-9264-z
Straube N, Iglésias SP, Sellos DY, Kriwet J, Schliewen UK (2010) Molecular phylogeny and node time estimation of bioluminescent lantern sharks (Elasmobranchii: Etmopteridae). Mol Phylogenet Evol 56:905-917. https://doi.org/10.1016/j.ympev.2010.04.042

Straube N, Li C, Claes JM, Corrigan S, Naylor GJP (2015) Molecular phylogeny of Squaliformes and first occurrence of bioluminescence in sharks. BMC Evol Biol 15(1):162. https://doi. org/10.1186/s12862-015-0446-6

Taniuchi T (1970) Variation in the teeth of the sand shark, Odontaspis taurus (Rafinesque) taken from the East China sea. Jpn J Ichthyol $17: 37-44$

Tomita T, Miyamoto K, Kawaguchi A, Toda M, Oka SI, Nozu R, Sato K (2017) Dental ontogeny of a white shark embryo. J Morphol 278:215-227. https://doi.org/10.1002/jmor.20630

Publisher's Note Springer Nature remains neutral with regard to jurisdictional claims in published maps and institutional affiliations. 